\title{
From our readers
}

\section{WHO PAYS FOR KNOWLEDGE?}

To the editor - The main purpose of basic research is to produce knowledge. In your Editorial and in the Commentary by A. M. Noll published in the May 2006 issue of Nature Materials, you protest against private companies that are more and more reluctant to pay for it. But who then must pay for knowledge and the people creating it? Who should pay to preserve the produced knowledge? Do we need to regulate how knowledge is distributed?

A. M. Noll argues that the academic environment and the peer-reviewed publishing process do not encourage really risky work and that universities and government laboratories are therefore disqualified from this task. Surely, the tax payer will not be happy to learn that their money is not in good hands and that governments seem unable to encourage their employees to create new knowledge. According to Noll, researchers in a private company have a better sense of mission and a better proximity to the real world, and therefore the public should fund industrial research activities instead. However, putting the two systems of knowledge production, public and private, into such opposition is not the way to answer the underlying fundamental question of who in our society should foot the bill for fundamental research.

First, we must decide whether it is good or not to continue to perform basic research. Although the answer seems straightforward, in many developed countries there are groups of people who are seriously questioning scientific activities, in particular those related to nuclear energy, genetically modified organisms or nanotechnology. Some are even asking to stop science entirely.

Second, assuming a democratic consensus that we need to continue scientific exploration, who will pay for and practise basic research: individual researchers, governments or private companies? The interest of individuals is obvious. It is the freedom of individuals to pursue scientific knowledge as part of their free time, for example to observe the sky, to construct a microscope or to solve a beautiful equation. This type of knowledge production has been common until very recent times. In modern society, however, the two remaining parties to pay for knowledge are the public and companies. The objective of a nation in paying for knowledge is the same as that of a private company: survive and outdo your competitors.

Third, as the president of a nation or chief executive of a private company you can build your own infrastructure for knowledge production: universities, governmental or industrial laboratories. But you can also wait for others to pay for knowledge. The two main reasons for a nation to create universities were the formation of elites through education and the support of brilliant individuals by putting up the necessary funds for their research. After centuries of non-organized knowledge production, this was seen as a key part of the independence of a nation. The main reason for private companies to create industrial research laboratories was to circumvent the costs of knowledge produced by others. In the middle of the twentieth century, and by virtue of the magic of modern communication, this was transformed into an in-house activity akin to sponsorship for the sake of human kind.

Nevertheless, the main body of fundamental scientific research achievements remains free to access, paid for by the public. Why then should a private company continue to pay for it in-house? In an open society, private companies as well as the taxpayer need to find the best place to produce high-quality knowledge at a minimum cost. In some ways, this requires a multinational way of thinking, and nations might hesitate to behave that way. An example is the problem of European research as opposed to European national research. For a private company, knowledge is like any other goods. If a pair of jeans, a bottle of wine or a mobile phone travel thousands of kilometres from their origin to the shop, why not knowledge as well?

Industrial research laboratories are not a relic, they are not neglecting basic research, they are just adapting to the world. They go after knowledge where it is less expensive to produce and therefore cheaper to be transformed into new technologies. Some nations are starting to act the same way, and we are far removed from a certain romantic ideal of creating knowledge for the fun of it. Certainly we do not have to accuse industrial laboratories of that.

\section{Joachim}

CEMES/CNRS, NanoSciences Group, 29 rue Jeanne Marvig, BP 4347, 31055 Toulouse Cedex 4, France

e-mail: joachim@cemes.fr 